\title{
Accumulation of Co by Several Species of Marine Bivalves
}

\author{
Taishi UedA*, Yuzuru Suzuki*, Ryoichi Nakamura* \\ and Motokazu NAKAHARA*
}

(Received December 7, 1981)

\begin{abstract}
To clarify the effect of chemical form on the accumulation of Co by organisms, a rearing experiment was performed, using ${ }^{80} \mathrm{Co}\left(\mathrm{CoCl}_{2}\right)$ as an inorganic compound and ${ }^{87} \mathrm{Co}$ cyanocobalamin as an organic one. The concentration factor of inorganic ${ }^{\circ 0} \mathrm{Co}$ for Gomphina melanaegis was calculated to be 360 and that of organic ${ }^{87} \mathrm{Co}$ was 650 . The effect of the difference of chemical form was not large in the accumulation of $\mathrm{Co}$ by bivalves. The excretion curve of ${ }^{60} \mathrm{Co}$ consisted of one component, while that of ${ }^{87} \mathrm{Co}$ showed two components. The effective half life of ${ }^{80} \mathrm{Co}$ was 31 days and that of the longer component of ${ }^{{ }^{57} \mathrm{Co}}$ in the body of $G$. melanegis was 98 days. A remarkably different distribution of Co was observed in the gills, liver, and kidney, suggesting different metabolism processes due to the chemical forms in the organs of the bivalves.

On the gel filtration profile of $\mathrm{Co}$ in the liver of $G$. melanaegis, inorganic ${ }^{\circ 0} \mathrm{Co}$ was incorporated in two constituents and organic ${ }^{87} \mathrm{Co}$ was in one component. Four species of bivalves G. melanaegis, Tridacna crocea, Spisula sachalinensis and Patinopecten yessoensis showed two peaks of ${ }^{80} \mathrm{Co}$ in the gel filtration profiles of their livers, while Anadara broughtonii and Tapes japonica showed three peaks.
\end{abstract}

We have studied the contamination of marine organisms by radioactive nuclides. In previous report, we qualitatively pointed out the different appearances of $\mathrm{Co}$ in the liver of the abalone due to chemical forms of $\mathrm{Co}$ in the environmental water, and described that accumulation and excretion of Co by some species of marine organisms could be varied by the chemical form of Co in sea water. ${ }^{1)}$ The purpose of this paper, therefore, is to know the quantitative effect of chemical form of $\mathrm{Co}$ on the accumulation by organisms and to obtain further information on the contamination of bivalves by Co. Then, following experiments were performed: 1) Accumulation and excretion of inorganic ${ }^{\circ \circ} \mathrm{Co}$ and organic ${ }^{87} \mathrm{Co}$ from sea water by Gomphina melanaegis and distribution of $\mathrm{Co}$ in the bivalve, 2) Combining of Co with constituents in the liver of $G$. melanaegis and 3) Combining of Co with constituents in the liver of other species of bivalves.

\section{Materials and Methods}

The chemical forms used were ${ }^{\circ 0} \mathrm{Co}\left(\mathrm{CoCl}_{2}\right)$ as an inorganic compound and ${ }^{87} \mathrm{Co}$ (cyanocobalamin) as an organic one. The specific activity of ${ }^{80} \mathrm{Co}$ and ${ }^{87} \mathrm{Co}$ was $93 \mathrm{mCi} / \mathrm{mg} \mathrm{Co}$ and 220 $\mu \mathrm{Ci} / \mu \mathrm{g}$ cyanocobalamin, respectively. The ${ }^{57} \mathrm{Co}$ solution was passed through a Chelex-100 column $(10 \times 1 \mathrm{~cm} \phi)$ for the elimination of inorganic Co and the effluent was used in the experiment. $\mathbf{B i}$ valves used are shown in Table 1.

Accumulation and Excretion of Inorganic ${ }^{60} \mathrm{Co}$ and Organic ${ }^{57} \mathrm{Co}$ from Sea Water by Gomphina melanaegis and Distribution of Co in the Bivalve

Twenty two individuals of $G$. melanaegis were reared in an aquarium with 100 liters of sea water containing $200 \mu \mathrm{Ci}{ }^{\circ 0} \mathrm{Co}$ for a week at $15^{\circ} \mathrm{C}$ without food. In another aquarium with six liters of sea water containing $30 \mu \mathrm{Ci}{ }^{57} \mathrm{Co}$, twenty two individuals were reared in the same manner. The radioactivity of ${ }^{\circ 0} \mathrm{Co}$ in the sea water scarecely decreased in the week, but that of ${ }^{87} \mathrm{Co}$ reduced from $1400 \mathrm{cpm} / \mathrm{ml}$ to a half in a day. Then ${ }^{57}$ Co cyanocobalamin was added every day for the keeping of $1400 \mathrm{cpm}$. The concentration of stable $C o$ in sea water used was estimated to be $0.14 \mu \mathrm{g} / l$ by the neutron activation analysis of sea water off our Institute. ${ }^{2)}$ Therefore, the raise of the concentration of stable $\mathrm{Co}$ in the rearing sea water was approximately $14 \%$ by the addition of inorganic ${ }^{\circ 0} \mathrm{Co}$ and less than $0.1 \%$ by the single addition of ${ }^{87} \mathrm{Co}$ cyanocobalamin. After the accumulation experiment, the bivalves were transferred into non-radioactive sea water for the

* Division of Marine Radioecology, National Institute of Radiological Sciences, Isozaki, Nakaminato,

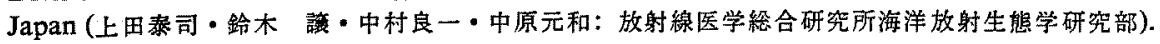


Table 1. Bivalves used

\begin{tabular}{llcc}
\hline Japanese name & \multicolumn{1}{c}{ Scientific name } & Averaged weight $(\mathrm{g})$ & Location \\
\hline Kotamagai & Gomphina melanaegis & 47.5 & Ibaraki and Fukushima \\
Ubagai & Spisula sachalinensis & 197.9 & \\
Akagai & Anadara broughtonii & 59.5 & $"$ \\
Asari & Tapes japonica & 44.8 & \\
Himejako & Tridacna crocea & 51.5 & Okinawa \\
Hotategai & Patinopecten yessoensis & 220.0 & Miyagi \\
\hline
\end{tabular}

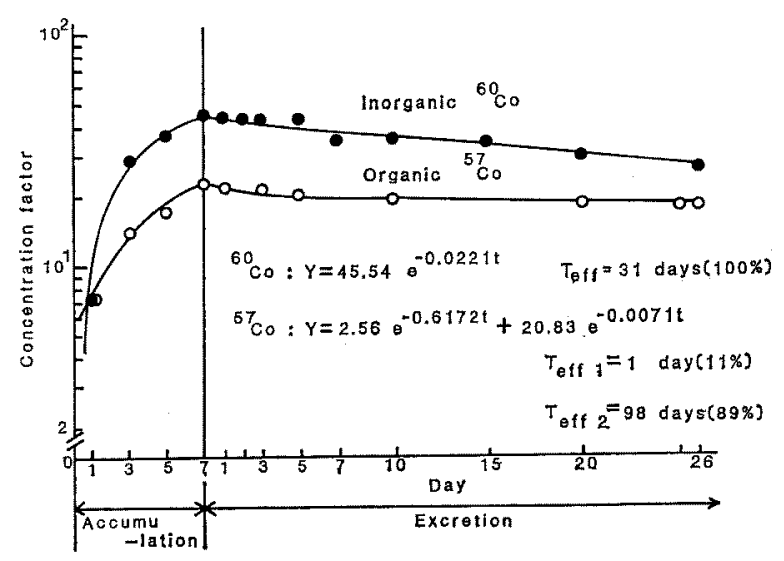

Fig. 1. Accumulation and excretion of Co by whole body of Gomphina melanaegis.

observation of the excretion of radioactive $\mathrm{Co}$. During the accumulation and excretion experiments, the radioactivity in whole body, shell and soft parts was periodically measured with a whole body counter (Packard 446). Furthermore, the soft parts were divided into liver, siphon, mantle, gill, kidney, foot muscle, adductor muscle, intestine and remainder (debris of tissues and organs), and their radioactivity was measured with an autowell $\gamma$-ray counter (Aloka JDC-752).

Combining of Co with Constituents in the Liver of G. melanaegis

For the comparison of the gel filtration profile of $G$. melanaegis with that of the abalone, ${ }^{1)}$ gel filtration was applied to the liver on Sephadex G-75 and Sepharose CL-4B. After three days' exposure, the sample of the liver was homogenized with $10 \mathrm{ml}$ of $0.025 \mathrm{M}$ Tris-acetate buffer solution (pH 8.4) by a high speed homogenizer $\left(2 \times 10^{4}\right.$ $\mathrm{rpm}$ ) and centrifuged at $1 \times 10^{4} \mathrm{rpm}$ for 30 minutes. The supernatant was applied on a Sephadex G-75 column $(75 \times 2 \mathrm{~cm} \phi)$ and a Sepharose CL-4B column $(60 \times 2.6 \mathrm{~cm} \phi)$. The gel filtration was performed at a flow rate of $40 \mathrm{~m} l /$ hour using the same buffer solution. Each $5 \mathrm{~m} l$ of the effluent was measured on the radioactivity of Co with the auto-well $\gamma$-ray counter. About $80 \%$ of the ratioactivity in the sample of the liver was found in the supernatant and the recovery of the radioactivity in the gel filtration was over $90 \%$. After the radioactivity was measured, the protein content in each fraction was monitored at $280 \mathrm{~nm}$ with a $\begin{array}{lll}\text { spectrophotometer (Hitachi } 124 & \text { DB). The }\end{array}$ molecular weight of protein in the sample of livers was estimated on the basis of a calibration curve that was obtained by the same treatment of materials such as Blue Dextran 2000 (MW: 2,000,000), Catalase (MW: 230,000), Ovalbumin (MW: 43,000), Ribonuclease A (MW: 13,700), Cytochrome C (MW: 12,400), Insulin (MW: 6,000 ) and ${ }^{57}$ Co cyanocobalamin (MW: 1,360).

\section{Combining of Co with Constituents in the Liver of Other Species of Bivalves}

For the examination of the combining of ${ }^{\circ 0} \mathrm{Co}$ with constituents in the livers of six species of bivalves, gel filtration was applied to the livers on Sephadex G-75. Three individuals of every species of bivalves were reared in two liters of sea water containing $4 \mu \mathrm{Ci}$ inorganic ${ }^{\circ 0} \mathrm{Co}$ for three days without food. Three livers of each species were composed as one sample, and the gel filtration was applied to one gram of the liver of each species. 


\section{Results and Discussion}

Accumulation and Excretion of Inorganic ${ }^{\circ} \mathrm{Co}$ and Organic ${ }^{87} \mathrm{Co}$ by Gomphina melanaegis and Distribution of Co in the Bivalve

Fig. 1 shows accumulation and excretion curves of $\mathrm{Co}$ by the whole body of $G$. melanaegis. The excretion of ${ }^{80} \mathrm{Co}$ from the whole body seemed to be one component and the curve was expressed by the following equation:

$$
Y=45.54 \mathrm{e}^{-0.0221 \mathrm{t}} \text {, }
$$

where $\mathrm{Y}$ : the radioactivity of ${ }^{80} \mathrm{Co}$ in the whole body, 0.0221: loss coefficient and $t$ : day. The biological half life $\left(T_{b}\right)$ was 32 days and the effective half life $\left(T_{\text {eff }}\right)$ was 31 days taking into account the physical decay of ${ }^{\circ} \mathrm{Co}$ (5.3 years). And the concentration factor at steady state was calculated to be 360 . Excretion of ${ }^{37} \mathrm{Co}$ consisted of two components and was expressed by the equation:

$$
Y=2.56 e^{-0.6172 t}+20.83 e^{-0.0071 t} \text {. }
$$

The radioactivity of the longer component was $89 \%$ to the initial radioactivity of the excretion experiment and its biological half life was 154 days, and the effective half life $\left(T_{\text {eff } 2}\right)$ was 98 days. The radioactivity of the shorter component was $11 \%$ and the effective half life $\left(\mathrm{T}_{\text {eff } 1}\right)$ was one day. The concentration factor was 650 . From these figures of the concentration factor, it is conceivable that the difference of chemical form of $\mathrm{Co}$ in sea water effects on the accumulation of Co by $G$. melanaegis with factor of two. LowMAN and TING reported that the finally apparent concentration factor of the soft parts of Donax denticulatus would be about 460 based on complexed $\mathrm{Co}$ in sea water and about 320 for inorganic Co. ${ }^{3)}$ Thus, a slight difference of these concentration factors was observed between inorganic and organic $\mathrm{Co}$ in sea water. Nevertheless, this difference is not serious because of the fluctuations of the concentration of radioactive $\mathrm{Co}$ in bivalves in natural ecosystems. The distributions of radioactivity in the shell and soft parts of $G$. melanaegis after seven days" exposure are shown in Table 2. Both inorganic ${ }^{80} \mathrm{Co}$ and organic ${ }^{87} \mathrm{Co}$ were dominantly found in the soft parts, although LowmaN and TrNG described that most of the ${ }^{67} \mathrm{Co}$ cobalamin was accumulated in the soft parts and inorganic ${ }^{8} \mathrm{Co}$ in the shell., The distributions of ${ }^{\circ} \mathrm{Co}$ and ${ }^{37} \mathrm{Co}$ in the soft parts of $G$. melanaegis are shown in Table 3. Remarkable difference in the distribution of Co was observed in the gill, liver and kidney, suggesting the different metabolism due
Table 2. Distribution of ${ }^{80} \mathrm{Co}$ and ${ }^{57} \mathrm{Co}$ in shell and

\begin{tabular}{|c|c|c|c|c|c|c|}
\hline & \multicolumn{3}{|c|}{${ }^{80} \mathrm{Co}$} & \multicolumn{3}{|c|}{${ }^{87} \mathrm{Co}$} \\
\hline & \multicolumn{2}{|c|}{ Weight } & \multirow{2}{*}{$\begin{array}{c}\text { Acti- } \\
\text { vity } \\
\%\end{array}$} & \multicolumn{2}{|c|}{ Weight } & \multirow{2}{*}{$\begin{array}{c}\text { Acti- } \\
\text { vity } \\
\%\end{array}$} \\
\hline & $\mathbf{g}$ & $\%$ & & g & $\%$ & \\
\hline Shell & 37.3 & 81 & 38 & 23.3 & 82 & 32 \\
\hline Soft parts & 8.5 & 19 & 62 & 5.2 & 18 & 68 \\
\hline
\end{tabular}
soft parts of G. melanaegis (7 days' exposure)

Table 3. Distribution of ${ }^{\circ 0} \mathrm{Co}$ and ${ }^{67} \mathrm{Co}$ in soft parts of $G$. melanaegis ( 7 days' exposure)

\begin{tabular}{lrr}
\hline & ${ }^{80} \mathrm{Co}$ & ${ }^{57} \mathrm{Co}$ \\
\hline Gill & 8.8 & 47.7 \\
Liver & 5.5 & 19.7 \\
Kidney & 40.0 & 1.8 \\
Mantle & 13.6 & 14.2 \\
Intestine & 1.5 & 0.3 \\
Foot muscle & 4.1 & 3.0 \\
Siphon & 2.1 & 1.0 \\
Adductor muscle & 2.5 & 0.7 \\
Remainder* & 21.9 & 11.6 \\
\hline
\end{tabular}

* debris of tissues and organs.

to chemical forms in the organs of the bivalve.

Combining of Co with Constituents in the Liver of G. melanaegis

The gel filtration profiles of radioactive $\mathrm{Co}$ in the liver of G. melanaegis are shown in Fig. 2, accompanied with an optical density curve at $280 \mathrm{~nm}$. After three days' exposure, the profile of ${ }^{\circ 0} \mathrm{Co}$ showed two dominant peaks, one between $20-60 \mathrm{~m} l$ and another between $140-190 \mathrm{~m} l$ of the elution volume. The constituents coincided with the peaks of protein. In the accumulation experiment, inorganic ${ }^{60} \mathrm{Co}$ combined with the constituent eluted between $20-60 \mathrm{ml}$ and $140-190 \mathrm{ml}$ was 37 and $39 \%$, respectively, of the total radioactivity in the gel filtration profile. The radioactivity $(\%)$ in each peak scarecely varied by the 3rd day in the excretion experiment. Therefore, inorganic ${ }^{80} \mathrm{Co}$ from sea water combined evenly with two constituents in the liver and was evenly excreted without transfer to any other constituent. On the other hand, the profile of organic ${ }^{87} \mathrm{Co}$ showed one peak between $20-60 \mathrm{ml}$. The molecular weight of this constituent was much higher than that of cyanocobalamin, suggesting the incorporation of cyanocobalamin in this constituent as already indicated in our previous report. ${ }^{1)}$ As seen in Fig. 2, the different metabolism of inorganic and organic Co may cause different concentration 


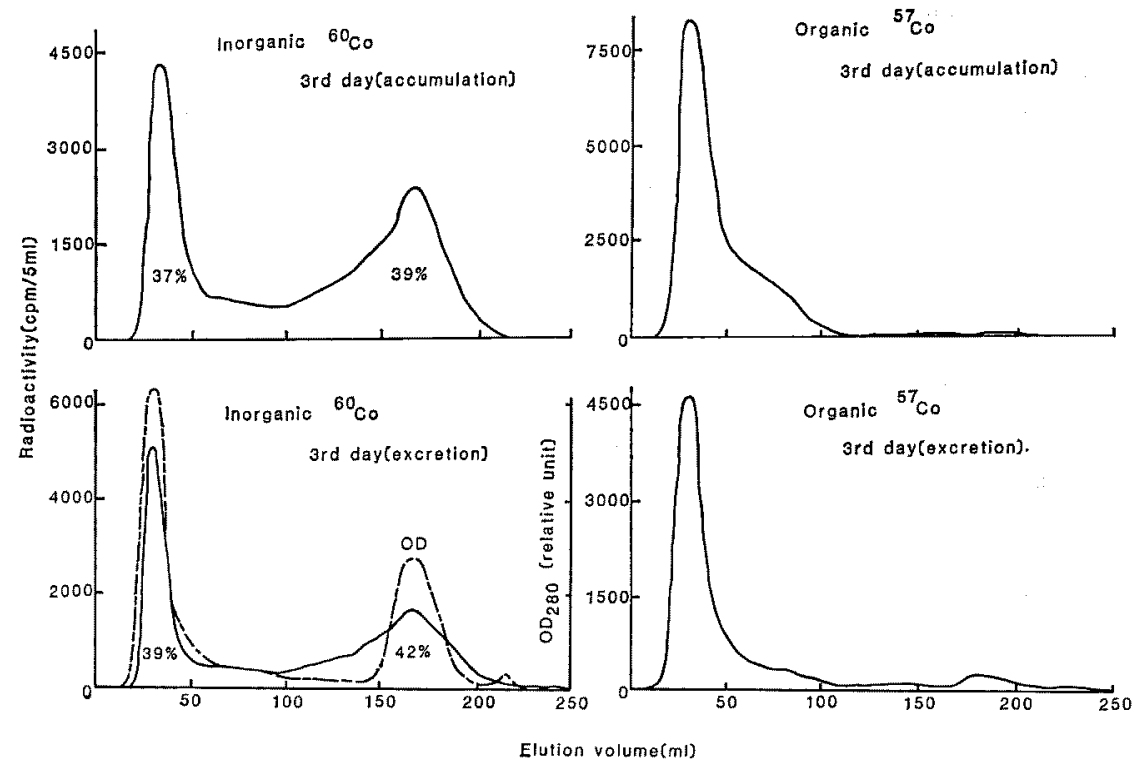

Fig. 2. Gel filtration profile of Co in liver of Gomphina melanaegis (Sephadex G-75). Percentage indicates radioactivity in peaks to total radioactivity in gel filtration profile.

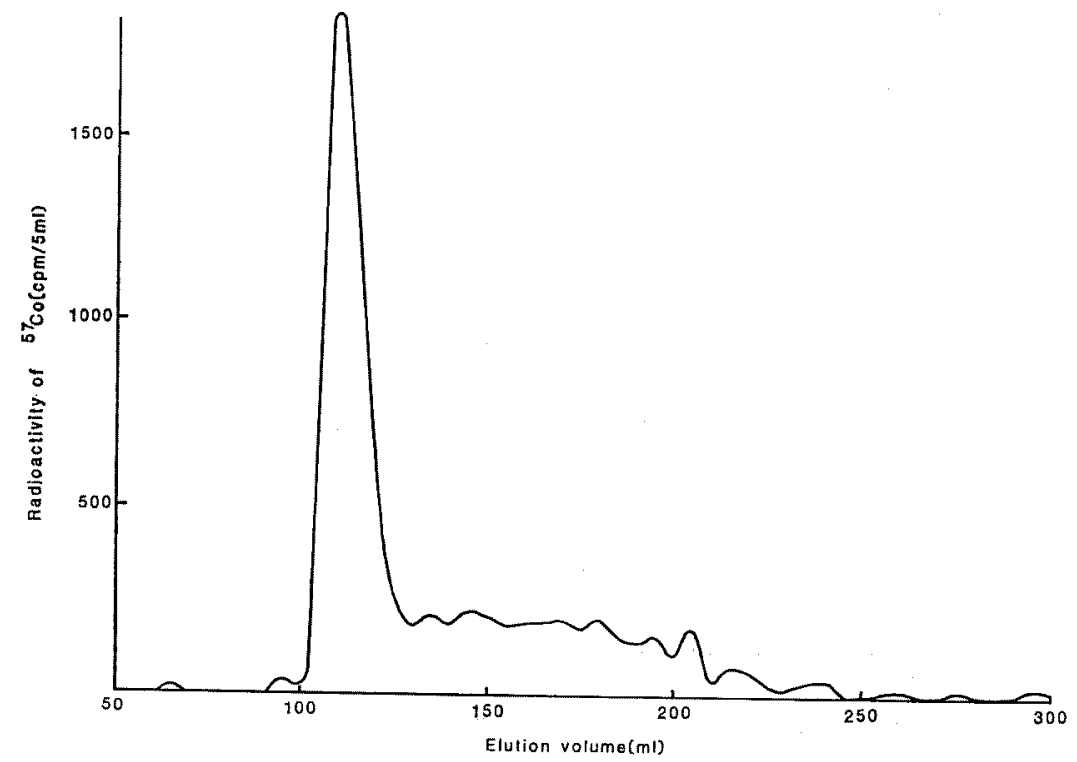

Fig. 3. Gel filtration profile of Co in liver of Gomphina melanaegis (Sepharose CL-4B).

factor, biological and effective half life. Further more, by gel filtration on Sepharose CL-4B (Fig. 3 ), the constituent combined with organic Co was eluted together with Blue Dextran (MW: $2 \times 10^{6}$ ). Previously, we reported that organic $\mathrm{Co}$ from water was incorporated in one constituent with a molecular weight of $4 \times 10^{4}$ in the liver of the abalone and this constituent maintained the activity of vitamin $B_{12 .}{ }^{1)}$ Probably, the metabolism of organic ${ }^{87} \mathrm{Co}$ in G. melanaegis (pelecypoda) is different from that in the abalone (gastropoda), although both of them showed one peak in the gel filtration profiles of organic ${ }^{\mathrm{B}} \mathrm{Co}$. Thus, chemical forms of $\mathrm{Co}$ in sea water affected the metabolism of Co 

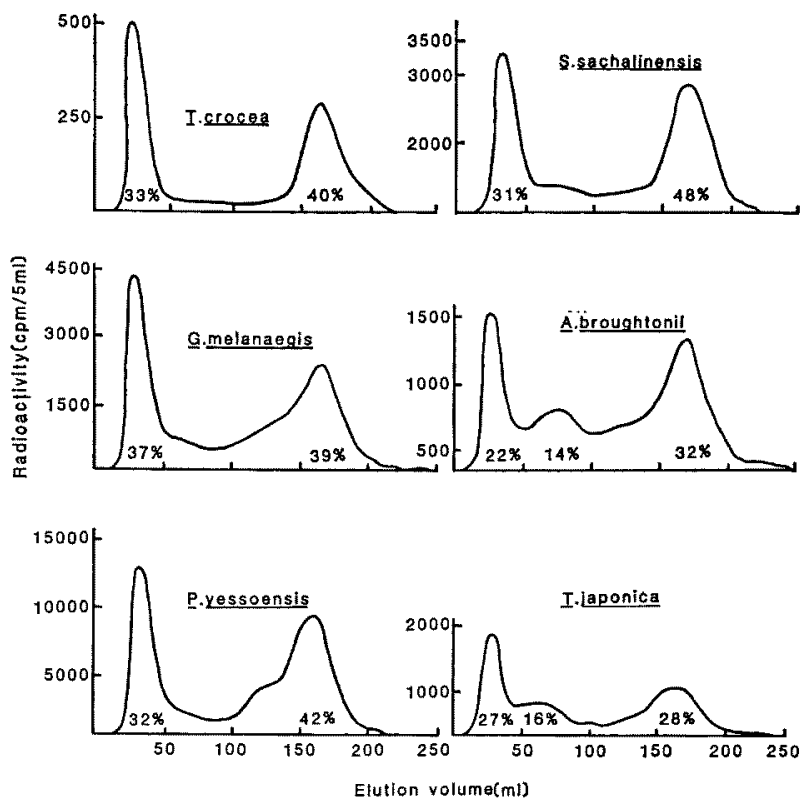

Fig. 4. Gel filtration profile of ${ }^{60} \mathrm{Co}$ in liver of bivalves. Percentage indicates radioactivity in peaks to total radioactivity in gel filtration profile.

in these molluscs.

Combining of Co with Constituents in the Liver of Other Species of Bivalves

The gel filtration profiles of ${ }^{60} \mathrm{Co}$ in the liver of six species of bivalves after three days' exposure are shown in Fig. 4. In the liver of $T$. crocea, $S$. sachalinensis, $G$. melanaegis and $P$. yessoensis, ${ }^{80} \mathrm{Co}$ was combined with two constituents eluted between $20-60 \mathrm{ml}$ and between $140-190 \mathrm{ml}$, and the radioactivity in the peak between $20-60 \mathrm{~m} l$ was 33 and that in $140-190 \mathrm{ml}$ was $42 \%$, in average, of the total radioactivity in the gel filtration profile. Inorganic ${ }^{\circ} \mathrm{Co}$ accumulated in the liver of $A$. broughtonii and $T$. japonica combined with three constituents eluted between 20-60 (MW: more than 80,000), 60-90 (MW: 10,000-20,000) and 140-190 $\mathrm{ml}$ (MW: less than 5,000) and the radioactivity in them was 25,15 and $30 \%$, in average, respectively. The profile of $A$. broughtonii showed a similarity to that of $T$. japonica. Nevertheless, A. broughtonii contains $\mathrm{Fe}$ in the blood pigment instead of $\mathrm{Cu}$ in other bivalves. Any relation between the metal in blood pigment and Co accumulation was not observed. The ${ }^{80} \mathrm{Co}$ profiles in the liver of Seriola purpurascens ${ }^{4)}$ and Octopus vulgaris ${ }^{51}$ showed two peaks by the 3rd day in the accumulation experiment. Therefore, it is conceivable that inorganic Co in sea water is incorporated in two kinds of protein in the liver of marine molluscs with the exception of occasional three kinds of protein.

Thus, the accumulation mechanism of metals by marine organisms seems to be approached by studying the combination between metals and constituent materials such as protein, polysaccharide and so on.

\section{References}

1) T. Ueda, Y. Suzuki, R. Nakamura, M. NakAHARA, and C. SHImIzu: J. Radiat. Res., 23, 99104 (1982) (in press).

2) H. SuzuKI: in "Radioecological Studies on Marine Environment"' (NIRS-R-3), 1974, pp. 55 (in Japanese).

3) F. G. Lowman and R. Y. TING: in "Radioactive Contamination of the Marine Environment" (Proc. of IAEA Sym.), 1973, pp. 369-384.

4) Y. Suzuki, R. Nakamura, M. Nakahara, and T. Ukda: Bull. Japan. Soc. Sci. Fish., 47, 261265 (1981).

5) M. Nakahara, T. Koyanagi, T. Ueda, and C. SHIMIZU: (submitted). 